\title{
ClubrootTracker: A Resource to Plan a Clubroot-Free Farm
}

\author{
Kevin Muirhead, ${ }^{1}$ Christopher D. Todd, ${ }^{2}$ Yangdou Wei, ${ }^{2}$ Peta Bonham-Smith, ${ }^{2}$ and \\ Edel Pérez-López ${ }^{2, \dagger}$ \\ ${ }^{1}$ University of Calgary, Calgary, Alberta, Canada \\ ${ }^{2}$ Department of Biology, University of Saskatchewan, Saskatoon, Saskatchewan, Canada
}

\begin{abstract}
Clubroot is a devastating disease affecting cruciferous crops worldwide. Clubroot was first described in the 13th century in Russia and from that moment has been affecting European, Asian, and American brassica production. Plasmodiophora brassicae is the clubroot causal agent, and it is an obligate intracellular parasite that, as soil-borne resting spores, can remain viable in soil for many years. This persistence in the soil is a major negative contributing factor to the management of clubroot disease and highlights the importance for brassica growers to have ready access to current information on the distribution of the pathogen. The interactive online tool ClubrootTracker (http://clubroottracker.ca) has been developed to enable users to view pathogen and disease presence in geographic locations across the world. ClubrootTracker, as described in this manuscript, has been developed to provide brassica farmers a tool that will contribute to clubroot management and aid in planning a clubroot-free farm. This tool is an open resource that has the main goal of acquisition of GPS information in reporting the pathogen or the disease by the researchers working with it around the world.
\end{abstract}

Clubroot has been associated with millionaire losses for farmers producing cruciferous crops such as canola (Brassica napus), broccoli (Brassica oleracea), and black mustard (Brassica nigra) worldwide (Bhering et al. 2017; Hwang et al. 2012). Clubroot has been present in East Europe since the 1200s (Dixon 2009), but it was not until 1877 that Plasmodiophora brassicae Woronin was described as the causal agent of clubroot disease (Woronin 1877). $P$. brassicae is a protist member of the supergroup Rhizaria (Burki et al. 2010), the most poorly understood group of unicellular eukaryotes. P. brassicae is also an obligate intracellular soil-borne parasite that can form resting spores that can remain viable in soil for up to 20 years (Peng et al. 2015; Wallenhammar 1996). Indeed, the persistence of the resting spores in the soil is the main reason why this disease is so difficult to manage by farmers (Hwang et al. 2012).

Clubroot is present in Australia and Oceania, Europe, Asia, and the Americas (Botero et al. 2019), but the specific fields affected by the disease are not well known, making it hard for farmers to develop conscientious management. The distribution of the pathogen, in Canada, has been registered by the Canola Council of Canada (https://www.canolacouncil.org/canola-encyclopedia/ diseases/clubroot/affected-regions/) using data collected by the Alberta, Manitoba, and Saskatchewan Provincial Agriculture Departments. In coordination with the Pest Surveillance Initiative, Manitoba Agriculture has created a searchable interactive map by postal code in identifying

\footnotetext{
${ }^{\dagger}$ Corresponding author: E. Pérez-López; edel.perez-lopez.1@ulaval.ca
}

Current address for E. Pérez-López: Département de Phytologie, Faculté des Sciences de l'Agriculture et de l'Alimentation, Université Laval, Québec City, Québec G1V 0A6, Canada.

"The $e$-Xtra logo stands for "electronic extra" and indicates there are supplementary materials published online.

The author(s) declare no conflict of interest.

Accepted for publication 7 May 2020.

\section{Funding}

This work was supported by Saskatchewan Agriculture Development Fund (SADF) and the Saskatchewan Canola Development Commission (SaskCanola) as a grant awarded to P.B.S., C.D.T., and Y.W.

\section{Keywords}

Plasmodiophora brassicae, pathogen distribution, management, brassica crops, cruciferous vegetables 
areas of infection by the pathogen (http://www.mbpestlab.ca/pest-maps/clubroot/?/pest-map/), whereas the Alberta and Saskatchewan Provincial Agriculture Departments report the presence of the pathogen through a static map (https://www.canolacouncil.org/canola-encyclopedia/ diseases/clubroot/affected-regions/). However, in other countries, this kind of information regarding the clubroot pathogen distribution is not available. During a recent meeting with farmers, a situation was reported in which a farmer bought cleaned machinery from another farmer located in an area previously reported to be affected by clubroot. The buyer did not reclean the machinery, and the cleaning performed on the machinery by the seller turned out to be insufficient to remove all soil-borne spores of the pathogen. The new piece of equipment introduced $P$. brassicae and clubroot to the buyer's farm. What if the farmer buying the machinery had access to a searchable online tool identifying the regions across Canada affected by clubroot? ClubrootTracker (http://clubroottracker.ca) was developed to address this type of situation; it is a tool that can be updated not only by us but also by any researcher around the world.

\section{What Is ClubrootTracker?}

ClubrootTracker (http://clubroottracker.ca) is an online tool freely available that consists of an interactive map tool for tracking $P$. brassicae (clubroot) around the world (Supplementary Fig. $1 A$ and $B$ ), although it could be modified and used to present the distribution of any other pathogen.

\section{How to Use ClubrootTracker}

To explain ClubrootTracker, we added mock geographic locations. ClubrootTracker, under the http://clubroottracker.ca address, directs users to start ClubrootTracker (Supplementary Fig. 1C). Users can type an address in the search bar of the Start ClubrootTracker home page (Supplementary Fig. 1C), http://clubroottracker.ca/clubroot/index.php. For example, if a farmer is interested in buying machinery from another farmer residing in Calgary, Alberta, a search for Calgary in ClubrootTracker will show a message that includes the location of the closest point where clubroot has been detected (Supplementary Fig. 1C). By clicking on this location highlighted on the map, the user will see the message that includes the description of the data and that clubroot and/or P. brassicae has been detected. In order to have complete transparency, the message popping up from the data points will also include the information of the researcher uploading the data (Supplementary Fig. 1C).

\section{ClubrootTracker Code and Data Availability}

ClubrootTracker is a web-based utility written in the Bootstrap version 3.3.7 (https:// getbootstrap.com/) web framework using leaflet.js (https://leafletjs.com), a JavaScript library for rendering the interactive map user interface. A Python utility was developed to convert GPS data into a GeoJSON formatted file, which can be used to render the data points corresponding to areas affected by clubroot. The code that comprises the ClubrootTracker is provided as a GitHub link (https://github.com/kevmu/ClubrootTracker). The code for ClubrootTracker is openly available to the scientific community and industry, and it allows the updating of GPS data, making it useful not only for Canadian farmers but also worldwide. To keep track of those users uploading GPS data, users intending to upload data need to log on for their session (under the tab Dashboard: http://clubroottracker.ca/login.php) (Supplementary Fig. 1D), but for that they first need to register (http://clubroottracker.ca/registration.php) (Supplementary Fig. 1E). In order to conclude the registration, users need to agree to the ClubrootTracker terms and conditions (Supplementary Fig. 1F), reassuring that the data uploaded is not breaking any confidentiality agreement with the farmers and/or owners of the land (Supplementary Fig. 1F). Once the registration is finished, the user uploading the data can start the process (Supplementary Fig. 1G), and once uploaded, they can start tracking (Supplementary Fig. 1H). A detailed guide of how to upload information to ClubrootTracker is provided here as Supplementary File 1. All the code for ClubrootTracker is free and available to download (http://clubroottracker.ca/downloads.php) (Supplementary Fig. 1I). 


\section{Other ClubrootTracker Features}

Active links from ClubrootTracker to the Canola Council of Canada (https://www.canolacouncil.org/), the Canola Encyclopedia (https://www.canolacouncil.org/canola-encyclopedia/ diseases/clubroot), Clubroot Control: Prevention and Management (https://www.canolacouncil. org/canola-encyclopedia/diseases/clubroot/control-clubroot), and a PDF clubroot sanitation guide (https://www.canolacouncil.org/media/530963/clubroot_sanitation_guide.pdf) (Supplementary Fig. 1J) can be found on the Links page (http://clubroottracker.ca/links.php). ClubrootTracker has been designed for use on a mobile device, via a web browser, to make it readily accessible for farmers to enhance their clubroot management strategy. A stand-alone mobile device application will be developed in the future to further facilitate the accessibility of the application and the overall user experience.

\section{Significance of ClubrootTracker}

Clubroot management in Canada and worldwide relies on two main strategies: (i) preventing the introduction of $P$. brassicae into noninfected fields, and (ii) managing clubroot disease to reduce its incidence and severity in infected fields (Gossen et al. 2015). Resting spores can adhere to soil particles and are readily dispersed through machinery or eroding soil (Rennie et al. 2015). Farm hygiene and biovigilance are strategies used to avoid the introduction of pathogen into fields through the movement of resting spores. A current, searchable tool, delivering the geographic distribution of the pathogen across the world, will greatly improve these strategies. Effective sanitization of machinery is essential to reduce the spread of the clubroot pathogen to new fields (Donald and Porter 2009; Hwang et al. 2014). Sanitization of machinery acquired from areas affected by the pathogen is key for effective clubroot management strategies (Diederichsen et al. 2014). ClubrootTracker will enable farmers to make better-informed decisions concerning equipment sanitation procedures before acquiring or borrowing machinery from infected areas.

\section{ClubrootTracker and Future Possibilities}

New data can be readily uploaded to ClubrootTracker. New windows and links to relevant information for farmers can also be included, making ClubrootTracker part of the Canola Encyclopedia. This tool can be readily expandable to include other diseases affecting canola in the prairies, such as aster yellows (Olivier et al. 2006), blackleg (Chen and Fernando 2005), stem rot (Morrall et al. 1976), and others, as long as the distribution of the disease and pathogen would be of importance to the farmer's management strategies.

\section{Literature Cited}

Bhering, A. S., do Carmo, M. G. F., Matos, T. M., Lima, E. S. A., and Sabrihno, N. M. B. A. 2017. Soil factors related to the severity of clubroot in Rio de Janeiro, Brazil. Plant Dis. 101:1345-1353.

Botero, A., García, C., Gossen, B. D., Strelkov, S. E., Todd, C. D., Bonham-Smith, P. C., and Pérez-López, E. 2019. Clubroot disease in Latin America: Distribution and management strategies. Plant Pathol. 68:827-833.

Burki, F., Kudryavtsev, A., Matz, M. V., Aglyamova, G. V., Bulman, S., Fiers, M., Keeling, P. J., and Pawlowski, J. 2010. Evolution of Rhizaria: New insights from phylogenomic analysis of uncultivated protists. BMC Evol. Biol. 10:377.

Chen, Y., and Fernando, W. G. D. 2005. First report of canola blackleg caused by pathogenicity group 4 of Leptosphaeria maculans in Manitoba. Plant Dis. 89: 339.

Diederichsen, E., Frauen, M., and Ludwig-Müller, J. 2014. Clubroot disease management challenges from a German perspective. Can. J. Plant Pathol. 36(Sup.1): 85-98.

Dixon, G. R. 2009. The occurrence and economic impact of Plasmodiophora brassicae and clubroot disease. J. Plant Growth Regul. 28:194-202.

Donald, C., and Porter, I. 2009. Integrated control of clubroot. J. Plant Growth Regul. 28 : 289-303

Gossen, B. D., Strelkov, S. E., Manolii, V. P., Rennie, D. C., Cao, T., Hwang, S.-F., Peng, G., and McDonald, M. R. 2015. Spread of Plasmodiophora brassicae on canola in Canada, 2003-2014: Old pathogen, new home. Can. J. Plant Pathol. 37:403-413.
Hwang, S.-F., Howard, R. J., Strelkov, S. E., Gossen, B. D., and Peng, G. 2014. Management of clubroot (Plasmodiophora brassicae) on canola (Brassica napus) in western Canada. Can. J. Plant Pathol. 36(Sup.1):49-65.

Hwang, S.-F., Strelkov, S. E., Feng, J., Gossen, B. D., and Howard, R. J. 2012. Plasmodiophora brassicae: A review of an emerging pathogen of the Canadian canola (Brassica napus) crop. Mol. Plant Pathol. 13:105-113.

Morrall, R. A. A., Dueck, J., McKenzie, D. L., and McGee, D. C. 1976. Some aspects of Sclerotinia sclerotiorum in Saskatchewan, 1970-75. Can. Plant Dis. Surv. 56:56-62.

Olivier, C., Galka, B., Murza, G., Hegedus, D., Peng, X., Séguin-Swartz, G., BoudonPadieu, E., and Barasubiye, T. 2006. Aster yellows disease survey in Saskatchewan, Canada, 2001-2006. Plant Prot. Dis. 1:124-126.

Peng, G., Pageau, D., Strelkov, S. E., Gossen, B. D., Hwang, S.-F., and Lahlali, R. 2015. A >2-year crop rotation reduces resting spores of Plasmodiophora brassicae in soil and the impact of clubroot on canola. Eur. J. Agron. 70:78-84.

Rennie, D. C., Holtz, M. D., Turkington, T. K., LeBoldus, J. M., Hwang, S.-F., Howard, R. J., and Strelkov, S. E. 2015. Movement of Plasmodiophora brassicae resting spores in windblown dust. Can. J. Plant Pathol. 37:188-196.

Wallenhammar, A. C. 1996. Prevalence of Plasmodiophora brassicae in a spring oilseed rape growing area in central Sweden and factors influencing soil infestation levels. Plant Pathol. 45:710-719.

Woronin, M. 1877. Plasmodiophora brassicae, der Organismus, der die unter dem Namen Hernie bekannte Krankheit der Kohlpflanzen verursacht. Arb. St. Petersburger Naturf. Ges. 8:169-201. 